\title{
Correction to: How will artificial intelligence and bioinformatics change our understanding of IgA Nephropathy in the next decade?
}

\author{
Roman David Bülow ${ }^{1}$ (D) $\cdot$ Daniel Dimitrov ${ }^{2,3}$ (D) Peter Boor ${ }^{1,4}$ (D) $\cdot$ Julio Saez-Rodriguez ${ }^{2,3,5,6}$ (D)
}

Published online: 7 May 2021

(C) The Author(s) 2021

\section{Correction to: Seminars in Immunopathology https://doi.org/10.1007/s00281-021-00847-y}

The original version of this article unfortunately contained a mistake. The title was incorrect. The corrected title is given above.

The original article has been corrected.

Open Access This article is licensed under a Creative Commons Attribution 4.0 International License, which permits use, sharing, adaptation, distribution and reproduction in any medium or format, as long as you give appropriate credit to the original author(s) and the source, provide a link to the Creative Commons licence, and indicate if changes were made. The images or other third party material in this article are included in the article's Creative Commons licence, unless indicated otherwise in a credit line to the material. If material is not included in the article's Creative Commons licence and your intended use is not permitted by statutory regulation or exceeds the permitted use, you will need to obtain permission directly from the copyright holder. To view a copy of this licence, visit http://creativecommons.org/licenses/by/4.0/.

Publisher's note Springer Nature remains neutral with regard to jurisdictional claims in published maps and institutional affiliations.
The online version of the original article can be found at https://doi.org/ 10.1007/s00281-021-00847-y

Peter Boor

pboor@ukaachen.de

$\triangle$ Julio Saez-Rodriguez

julio.saez@uni-heidelberg.de

1 University Hospital RWTH Aachen, Institute of Pathology, Aachen, Germany

2 Faculty of Medicine, Heidelberg University, Heidelberg, Germany

3 Institute for Computational Biomedicine, Heidelberg University Hospital, Bioquant, Heidelberg, Germany

4 Department of Nephrology and Immunology, University Hospital RWTH Aachen, Aachen, Germany

5 Faculty of Medicine, Joint Research Centre for Computational Biomedicine (JRC-COMBINE), 52074, RWTH Aachen University, Aachen, Germany

6 Molecular Medicine Partnership Unit, European Molecular Biology Laboratory and Heidelberg University, Heidelberg, Germany 